I BIENAL LATINOAMERICANA DIDH

\title{
Diálogo multinivel en los sistemas internacionales de protección de los derechos humanos: ¿Hacia dónde vamos?
}

\author{
Multilevel dialogue in international systems for the protection \\ of human rights: Where are we going?
}

\section{Marie-Christine Fuchs (iD) y Miguel Barboza López (iD Fundación Konrad Adenauer, Alemania}

\begin{abstract}
RESUMEN El diálogo multinivel en los sistemas de protección de los derechos humanos presenta desafíos a nivel técnico-metodológico, jurisprudencial y político. A partir del principio pro homine y de solidaridad, es necesario que exista una comunicación constante entre los diferentes tribunales regionales de derechos humanos que coadyuven a la defensa de la persona humana. En el presente artículo abordaremos este tema desde diferentes posturas jurisprudenciales y académicas.
\end{abstract}

PALABRAS CLAVE Diálogo multinivel, derechos humanos, sistemas internacionales de protección.

ABSTRACT Multilevel dialogue in human rights protection systems presents challenges both at the technical-methodological, jurisprudential and political levels. Based on the pro homine and solidarity principles, it is necessary that there is constant communication between the different regional human rights courts that contribute to the defense of the human being. In this article we will address these issues from different jurisprudential and academic positions.

KEYWORDS Multilevel dialogue, human rights, international systems of protection. 


\section{Introducción}

El 28 y 29 de noviembre de 2018 se celebró en Santiago de Chile la Primera Bienal Latinoamericana de Estudios sobre Derecho Internacional de los Derechos Humanos, organizada por la Universidad de Chile y el Programa Estado de Derecho para Latinoamérica de la Fundación Konrad Adenauer, entre otras instituciones.

La Bienal fue un evento propicio para analizar cómo el ordenamiento jurídico internacional ha evolucionado en estos últimos 70 años desde la adopción de la Declaración Universal de los Derechos Humanos. Evolución que se ha visto reflejada en la elaboración de innumerables convenios internacionales e interamericanos; la creación de diversas cortes y otros órganos encargados en exclusiva de la promoción y protección de los derechos humanos; y la aprobación de nuevas constituciones que acogieron dichos estándares.

Pese a estos avances, la Bienal también reflejó tres grandes desafíos: el primero, de orden técnico-metodológico, plasmado en la brecha de implementación de la norma garantista y su justiciabilidad efectiva y eficiente para el ciudadano; el segundo, de orden jurisprudencial, debido a la falta de coherencia entre los diferentes pronunciamientos de las cortes a nivel nacional y con los organismos internacionales y regionales de derechos humanos; y el tercero, de orden político, reflejado en la falta de voluntad política y reforzada con las trabas burocráticas y la práctica de algunos Gobiernos, a veces con crecientes tendencias autoritarias y populistas, que impiden la implementación de políticas y planes que garanticen los derechos humanos de sus ciudadanos. Estos desafíos son un llamado hacia una solución propositiva, como es el diálogo multinivel.

A partir de lo anterior, las instituciones organizadoras de la Bienal hemos decidido presentar este libro, que aborda diversos temas discutidos en el evento por ponentes de América Latina, el Caribe y la Unión Europa, con el fin de interiorizar, reflexionar y profundizar los debates y conceptos. Por parte del Programa Estado de Derecho para Latinoamérica, nos gustaría centrarnos, en este primer capítulo, en la importancia del diálogo multinivel, pues es un tema medular que necesita ser abordado para fortalecer nuestros mecanismos de protección y promoción de derechos humanos en todos los niveles, tomando en cuenta las diversas y plurales necesidades que aquejan a nuestras regiones a nivel mundial.

\section{Desafíos actuales frente al diálogo y la urgencia de abordarla}

Aunque la protección multinivel de los derechos humanos conlleva múltiples oportunidades y - bien aplicada e interpretada- beneficia al justiciable, en la práctica sus ventajas no siempre son evidentes, $y$ hasta incluso son ignoradas por nuevas ten- 
dencias políticas nacionalistas. Los desafíos para concretar un diálogo multinivel son múltiples, como a continuación abordaremos.

\section{Desafíos técnico-metodológicos}

Desde el punto de vista metodológico, el aplicador de una multiplicidad de diferentes normas de protección de los derechos humanos desde lo internacional a lo local se enfrenta a la dificultad no solo de conocer las interpretaciones que les han dado los tribunales o cortes constitucionales, regionales e internacionales, sino también de sortear el -a primer vista - complejo problema de su jerarquía normativa y del control de convencionalidad. ¿Cuándo se aplica determinada carta de derechos humanos y qué hacer en caso de conflicto entre las diferentes disposiciones de derechos humanos? No solo para los operadores jurídicos, sino también para la política y la enseñanza del derecho, esta consagración de los derechos fundamentales multinivel en forma de principios, de normas generales y abstractas, representa un reto de interpretación, argumentación y aplicación del derecho interno de conformidad con los principios convencionales. ${ }^{1}$

Desde hace décadas tanto jueces como académicos se esfuerzan para hacer frente a estos desafíos metodológicos desarrollando nuevas herramientas de interpretación jurídica, que complementan a las medidas hermenéuticas clásicas. El más conocido en América Latina es el llamado «control de convencionalidad», mediante el cual se bajan los estándares interamericanos de derechos humanos y su jurisprudencia a nivel local. ${ }^{2}$

No obstante, en la práctica jurídica de los países latinoamericanos, el control de convencionalidad ha sido en muchos casos abordado desde el principio de subsidiaridad y no con un «espíritu» de complementariedad. Con cierta rigidez, los Estados insisten en que los problemas jurídicos se deben resolver desde el nivel más bajo de la jerarquía normativa, el más cercano al ciudadano, y con preponderancia total a la propia constitución. En muchos casos, ignoran que los tratados internacionales en principio no pueden regular todas las situaciones jurídicas, políticas y sociales de los Estados, sino que van complementando las herramientas y prácticas internas de los Estados de protección de derechos. En este sentido, la Corte Interamericana de Derechos Humanos (Corte IDH) ha señalado que el principio de complementariedad significa que el sistema de protección de derechos humanos

1. Sobre la obligación de los funcionarios como jueces y operadores judiciales, véase Meléndez (2012: 145-146); sobre los retos del derecho público en el contexto de la globalización, véase Serna de la Garza (2017: 201-204).

2. Sentencia del caso Almonacid Arellano y otros con Chile, Corte Interamericana de Derechos Humanos, excepciones preliminares, fondo, reparaciones y costas, 26 de septiembre de 2006, párr. 124. 
instaurado a nivel regional no sustituye a las jurisdicciones nacionales, sino que las complementa. ${ }^{3}$

En línea con lo anterior, por el principio de complementariedad, estos tratados pueden modificarse o pueden irse forjando nuevos tratados tomando en cuenta la experiencia práctica de los Estados. Por ejemplo, el Convenio 169 sobre pueblos indígenas y tribales de la Organización Internacional del Trabajo de 1989, desde su génesis no regulaba la situación de los pueblos indígenas en aislamiento y contacto inicial. No obstante, con el pasar del tiempo, y tomando en cuenta la experiencia de los países de las Américas, en 2016 la Organización de los Estados Americanos reguló esta situación a través del artículo 26 de la Declaración Americana sobre los Derechos de los Pueblos Indígenas.

Esta visión ayuda a superar la rigurosidad del principio de subsidiariedad y a avanzar hacia una mayor protección de los derechos humanos (Huneeus, 2011: 493; Soley y Steininger, 2018). De lo contrario, los órganos regionales e internacionales están obligados a intervenir en caso de que las autoridades locales sean incapaces de garantizar la protección efectiva de los derechos fundamentales de sus ciudadanos (Carozza, 2003: 38-79; Negishi, 2018: 1-32).

Es de aclarar que los instrumentos internacionales de derechos humanos no requieren de un grado de especificidad estricto, pues esto es competencia de cada uno de los Estados. De lo contrario, los organismos internacionales podrían llegar a ser denunciados al desbordar sus funciones y trastocar la soberanía estatal. Para ello, es esencial que los Estados hagan suyos estos estándares y adopten normas específicas que los jueces pueden aplicar a nivel local.

\section{Desafíos jurisprudenciales}

Siguiendo la lógica del apartado anterior, el desarrollo jurisprudencial coherente a nivel local, regional e internacional representa un gran desafío en la actualidad. Se puede observar que, a nivel local, diversos jueces no dialogan entre sí para resolver temas que comparten el mismo problema jurídico. ${ }^{4}$ Misma situación puede presen-

3. Sentencia del caso Tarazona Arrieta y otros con Perú, Corte Interamericana de Derechos Humanos, excepción preliminar, fondo, reparaciones y costas, serie C núm. 286, 15 de octubre de 2014, párr. 137; sentencia del caso Comunidad Campesina de Santa Bárbara con Perú, excepciones preliminares, fondo, reparaciones y costas, serie C núm. 299, 1 de septiembre de 2015, párr. 159; sentencia del caso Duque con Colombia, excepciones preliminares, fondo, reparaciones y costas, serie C núm. 310, 26 de febrero de 2016, párr. 128.

4. En Perú, por ejemplo, en el tema de consulta previa de pueblos indígenas, en el caso Majes Siguas II, el juez de la Corte Superior de Justicia de Cusco rechazó el derecho a la consulta previa que tienen las comunidades campesinas de Espinar, pese a que con anterioridad este derecho ya había sido reconocido a nivel judicial en otros casos. Lo mismo sucede en el caso Jatucachi, en el cual el juez de la Corte Supe- 
tarse a nivel regional o universal con los derechos humanos, o entre estos últimos y los sistemas judiciales o administrativos nacionales, ${ }^{5}$ lo que lleva a una falta de seguridad jurídica para el ciudadano.

No se requiere que exista plena uniformidad o igualdad en el desarrollo de estándares sobre un mismo tema, pues las circunstancias caso a caso son diferentes y pueden variar; mas sí es necesario que haya coherencia frente a estándares internacionalmente reconocidos tanto en su formulación y aplicación. Por ejemplo, la Corte Internacional de Justicia, en el caso Ahmadou Sadio Diallo (República de Guinea con República Democrática del Congo), expresó lo siguiente:

Aunque el tribunal no está obligado en el ejercicio de sus funciones judiciales a ajustar su interpretación del Pacto [Internacional de Derechos Civiles y Políticos] al del Comité [Derechos Humanos], entiende que debe dar gran consideración a la interpretación adoptada por este organismo independiente, creado especialmente para supervisar la aplicación de ese tratado. Ello hace a la necesidad de claridad y esencial coherencia del derecho internacional, como también a la seguridad jurídica, que es un derecho de las personas beneficiarias de los derechos garantizados, como de los Estados vinculados a respetar las obligaciones convencionales (el énfasis es nuestro). ${ }^{6}$

Para lograr esa coherencia, se requiere la aplicación del control de convencionalidad, el cual, como ya hemos señalado, tiene que ser visto desde su formulación e implementación bajo el principio de complementariedad. En ese sentido, si bien los organismos internacionales desarrollan estándares jurisprudenciales a partir de experiencias locales, son los Estados los que complementan el desarrollo jurisprudencial internacional y están también sometidos a su legislación local, que puede o no ser aún más vanguardista.

\section{Desafíos políticos}

Por otro lado, y desde una perspectiva más desafiante, los sistemas regionales e internacionales de derechos humanos están enfrentando resistencias políticas y judiciales crecientes y endémicas por parte de algunos Estados. En especial, si los órganos de estos sistemas se ocupan de asuntos políticamente sensibles o que tocan al núcleo de la soberanía estatal. En muchos casos, los Estados miembros, aludiendo a su situación específica y a las peculiaridades nacionales, que según ellos no fueron tomadas

rior de Justicia de Puno, en primera instancia, declaró improcedente la demanda, mientras que la Sala superior revocó dicha decisión señalando que sí tienen derecho a la consulta previa.

5. Puede apreciarse la diferencia interpretativa de la Corte Interamericana de Derechos Humanos y el Tribunal Europeo de Derechos Humanos en los casos de libertad de expresión.

6. Caso Ahmadou Sadio Diallo (República de Guinea con República Democrática de Congo), Corte Internacional de Justicia, 30 de noviembre de 2010, párr. 66. 
en suficiente consideración, se niegan de manera más o menos abierta a cumplir con el orden jurisprudencial de los tribunales regionales o internacionales de derechos humanos (Burgorgue-Larsen, 2011: 190).

Muchos Estados miembros de sistemas regionales o internacionales de protección de derechos humanos, sobre todo los que cuentan con Gobiernos con tendencias nacionalistas, populistas y hasta autoritarias, no quieren, o incluso creen que no pueden, cumplir con el orden jurisprudencial de los órganos, como el Sistema Interamericano de Derechos Humanos o el Sistema Europeo de Derechos Humanos (Burgorgue-Larsen, 2011: 190). Esto se debe a varios aspectos: una combinación de falta de voluntad y oportunidad política; restricciones presupuestales y técnicas; y conceptos morales y sociales tradicionales que todavía prevalecen, y que son sujetos a cambios constantes.

En este contexto surgieron las discusiones recientes sobre un mayor margen de apreciación de las cortes nacionales en la aplicación de la jurisprudencia de las cortes regionales, como lo solicitaron los Gobiernos de Argentina, Brasil, Colombia, Chile y Paraguay en una declaración enviada a la Comisión Interamericana de Derechos Humanos en abril de 2019. Estos Estados solicitaron mayor respeto al principio de subsidiariedad como base de distribución de competencias en el Sistema Interamericano, y la introducción de un margen de autonomía o apreciación en la aplicación de decisiones del Sistema, algo que históricamente le ha sido ajeno.? Paradójicamente, la declaración invoca argumentos de soberanía propia similares a los usados hace unos años por Gobiernos como el de Hugo Chávez en Venezuela, y también de Evo Morales en Bolivia. ${ }^{8}$ Posturas que, de ser implementadas o convertirse en tendencia en la región, podrían debilitar y politizar gravemente el sistema de protección regional de derechos humanos en América Latina.

En Europa se pueden identificar tendencias similares. Aunque la Declaración de Copenhague de abril de 2018 fue mucho más favorable de lo que se esperaba, hay fuertes tendencias dentro de los Estados miembros del Consejo de Europa a reforzar la naturaleza subsidiaria del Sistema Europeo de Derechos Humanos de Estrasburgo y favorecer la institucionalización del valor jurídico del margen de apreciación estatal.

En casos extremos, estas tendencias políticas de reorientación hacia la soberanía nacional han servido a algunos Gobiernos de justificación para salirse por completo de sistemas regionales o internacionales de protección de derechos humanos. Al

7. «Comunicado de prensa Ministerio de Relaciones Exteriores y Ministerio de Justicia y Derechos Humanos sobre Sistema Interamericano de Derechos Humanos», Ministerio de Relaciones Exteriores, 23 de abril de 2019, disponible en https://bit.ly/2EO1R9o.

8. «Bolivia podría retirarse de la $\mathrm{CIDH}$, El Espectador, 18 de marzo de 2013, disponible en https:// bit.ly/2QFpHa3. 
nivel interamericano, contamos con el desafortunado caso de Venezuela, país en el cual la jurisprudencia de la Corte IDH ha quedado por completo desarraigada. ${ }^{9}$ En Europa la situación no es menos preocupante: Estados como Rusia o Turquía tejen nuevos argumentos para ignorar la jurisprudencia del Tribunal Europeo de Derechos Humanos (TEDH), acudiendo, entre otros, al concepto de la identidad constitucional. Al nivel internacional, toca mencionar la renuncia de Estados Unidos al Pacto Global sobre Migración de las Naciones Unidas, para dar solo un ejemplo.

Una forma más sutil - pero no menos preocupante- de boicotear el trabajo de mecanismos regionales e internacionales de derechos humanos es la práctica creciente de algunos Estados de quitar los fondos a sus respectivos órganos. Esto resulta en la reducción de personal, lo que tiene consecuencias nefastas para su funcionamiento. Como ejemplo, podemos mencionar la crisis financiera que atravesaron en el 2016 la Corte IDH y la CIDH. ${ }^{10}$

Teniendo en cuenta estos tres desafíos, para las cortes locales de los países latinoamericanos se plantea la cuestión de si, y en qué sentido, esta arquitectura multinivel afecta su jurisprudencia, y cómo entrar en un diálogo fecundo con los tribunales de los otros sistemas de protección de derechos humanos. Del mismo modo, esta falta de diálogo a nivel jurisprudencial multinivel tiene un impacto severo en la adopción de políticas públicas a nivel estatal, e impide que entre los Estados exista un diálogo consensuado para una mayor protección de los derechos humanos.

\section{El diálogo como componente esencial para quebrar los desafíos en la protección y promoción de los derechos humanos}

A partir de estos tres desafíos, y con la convicción de defender a nuestras democracias liberales y la protección multinivel de derechos, urge la búsqueda de herramientas efectivas y prometedoras para hacer frente a estos retos o - como lo han llamado algunos - combatir el creciente backlash (Soley y Steininger, 2018: 237-257). Aparte de una jurisprudencia bien argumentada, fundada y ponderada de órganos internacionales y regionales, capaz de convencer a los Estados, en nuestra opinión, el instrumento más prometedor es el diálogo franco e interdisciplinario entre actores a diferentes niveles. Eso, porque incluso la mejor jurisprudencia no garantiza que los Estados miembros de un respectivo sistema regional o internacional lo cumplan. Teniendo en cuenta, por ejemplo, el bajo nivel de cumplimiento de las sentencias de

9. «CIDH deplora medidas represivas adoptadas por Venezuela frente a protestas y condena la secuela de muertos y heridos», Comisión Interamericana de Derechos Humanos, 9 de mayo de 2017, disponible en https://bit.ly/3gKNOP7.

10. Silvia Ayuso, «La CIDH se queda sin fondos para defender los derechos humanos en las Américas», El País, 23 de mayo de 2016, disponible en https://bit.ly/2QFUN11. 
la Corte IDH en los Estados americanos, se evidencia que sin voluntad sociopolítica hay pocas oportunidades de que se logre una implementación efectiva de la normatividad regional e internacional al nivel nacional. Es justamente esta voluntad sociopolítica la que se busca a través del diálogo.

El diálogo es definido como un proceso incluyente que «reúne a un conjunto diverso de voces para crear un microcosmos de la sociedad en general». ${ }^{11}$ Esto implica aprender y no solo conversar; es decir, el diálogo no es un proceso que implique únicamente sentarse alrededor de una mesa, sino modificar la forma en que las personas hablan, piensan y se comunican entre ellas..$^{12}$

El diálogo como un «microcosmos» o un «ecosistema» debe tener un amplio criterio reformador, es decir, buscar avanzar en los objetivos comunes de las entidades o personas que dialogan: la garantía de la dignidad de la persona humana (Carozza y González, 2017: 436).

Para hacer efectivo un diálogo con esas características, es esencial aplicar los principios de solidaridad internacional y pro homine. Principios que se articulan entre sí y que dan el soporte internacional para lograr un diálogo multinivel fructífero y efectivo.

\section{Solidaridad internacional}

La solidaridad internacional, como un principio general del derecho (Higgins, 1994), ha sido entendida como «un producto de la historia social, en el entendimiento de que, con el tiempo, aparecerán en la comunidad internacional nuevas reclamaciones justificadas que deberán ser tratadas y resueltas a fin de proporcionar a las personas un nivel de protección más elevado». ${ }^{13}$

Las condiciones sociales, económicas y culturales en una sociedad cambian con el tiempo, por lo que se requiere abordar las problemáticas que puedan surgir de estas condiciones y resolverlas a través de un diálogo constante y plural de actores. Este diálogo entre los Estados y los demás actores sociales, como las empresas, la academia y la sociedad civil en general, demuestra un reconocimiento explícito de la solidaridad internacional como principio de derecho internacional. ${ }^{14}$

A nivel universal, se ha podido observar la aplicación del principio de solidaridad internacional en el abordaje de complejas situaciones jurídicas que por necesidad requieren acuerdos políticos previos con todos los actores sociales. Un ejemplo es el evento en vísperas del Foro Mundial sobre los Refugiados de Naciones Unidas en

11. «Importancia del diálogo para la prevención de conflictos y la construcción de paz», Programa de Naciones Unidas para el Desarrollo, febrero de 2009, p. 2, disponible en https://bit.ly/2YR6JkZ.

12. «Importancia...», 3 .

13. «Derechos humanos y solidaridad internacional», Organización de las Naciones Unidas, Asamblea General, Resolución A/HRC/12/27, 22 de julio de 2009, párr. 11.

14. «Derechos humanos...», párr. 13. 
2019, en el que se lanzó la plataforma de apoyo para el Marco Regional de Respuesta al Desplazamiento Forzado en Centroamérica (MIRPS). En dicho evento, el presidente de Costa Rica, Carlos Alvarado Quesada, señaló:

Si nos escuchamos los unos a los otros y trabajamos como una comunidad regional y global, encontraremos soluciones conjuntas a lo que está pasando en nuestros países [...]. El MIRPS provee una oportunidad regional, y debemos asegurarnos de que funcione. ${ }^{15}$

La declaración del presidente de Costa Rica es potente, ya que enlaza el principio de solidaridad internacional con el trabajo en conjunto entre todos los actores. Esto implica atender las reclamaciones actuales como un todo dialógico, que afecta a todos por igual, pero con efectos diferenciados según la realidad nacional o regional de cada país.

Por otro lado, la solidaridad en el diálogo implica tolerancia, es decir, que la capacidad de escucha sea a tal nivel de poder razonar en conjunto, sin sesgos políticos, y comprendiendo que las posturas adoptadas en un tema se pueden deber a las realidades tan diversas que enfrentamos. $\mathrm{Al}$ respecto, Naciones Unidas, entre sus pronunciamientos llamando al diálogo para la resolución de conflictos sociales, instó al diálogo y tolerancia en Nicaragua por los actos de represión recurrentes contra periodistas y medios de información críticos al Gobierno. Su portavoz, Stephan Durarric, señaló que «solo el diálogo inclusivo en un ambiente de tolerancia y paz puede conducir a soluciones duraderas». ${ }^{16}$

\section{Principio pro homine}

El principio pro homine o pro personae, ${ }^{17}$ gestado por primera vez por el entonces juez de la Corte IDH Rodolfo E. Piza, es un «criterio fundamental [que] impone la naturaleza misma de los derechos humanos, la cual obliga a interpretar extensivamente las normas que lo consagran o amplían y restrictivamente las que los limitan o restringen». ${ }^{18}$ El principio pro homine es un principio adicional de interpretación jurídica. Significa adoptar la interpretación más generosa posible cuando se trata de derechos otorgados al ciudadano, mientras que las normas que imponen deberes o

15. «Estados, sector privado, sociedad civil se unen en apoyo para Centroamérica», Oficina del Alto Comisionado de las Naciones Unidas para los Refugiados, 16 de diciembre de 2019, disponible en https://bit.ly/3bcvaym.

16. «La ONU insta al diálogo y la tolerancia en Nicaragua», Noticias ONU, 18 de diciembre de 2018, disponible en https://bit.ly/34Sfy1T.

17. Sobre el principio pro personae, véase Nogueira Alcalá y Aguilar Cavallo (2018: 239-265).

18. Opinión separada del juez Rodolfo E. Piza Escalante en «Exigibilidad del derecho de rectificación o respuesta (arts. 14.1, 1.1 y. 2 Convención Americana sobre Derechos Humanos)», Corte Interamericana de Derechos Humanos, Opinión Consultiva OC-7/86, serie A núm. 7, 29 de agosto de 1986, párr. 36. 
limitan el gozo de los derechos fundamentales deben ser interpretadas de manera restrictiva, sin importar a qué nivel de la «jerarquía normativa» se encuentren (Pinto, 1997: 163). Justamente por este último aspecto, este principio es al mismo tiempo una propuesta proactiva y garantista de la Corte IDH de resolver conflictos de jerarquías de normas, que da preponderancia a la norma que protege mejor a los derechos del ciudadano (Hernández, 2014). Además, es un criterio fundamental para orientar el diálogo de manera armónica y en múltiples niveles.

Aunque el principio pro homine llega a sus límites cuando diferentes derechos de dos o más individuos entran en conflicto y el juzgador tiene que decidir qué derecho prevalecerá, su implementación efectiva es una de las tareas más urgentes para combatir la brecha que todavía existe entra las normas y las realidades, sobre todo latinoamericanas, para que los derechos humanos se materialicen de manera efectiva. ${ }^{19}$ Además, este principio es la respuesta más coherente que podemos dar a los que todavía ven el ecosistema de derechos humanos como un sistema estático de jerarquías y lo argumentan bajo el principio de subsidiariedad. En nuestra opinión, dar prioridad a la norma que más protege a la persona tiene la más alta legitimidad fáctica y humanista, más que los conceptos tradicionales de soberanía estatal.

Ahora bien, la aplicación del principio pro homine en los diálogos debe darse tanto a nivel de los sistemas del derecho interno (Waters, 2017), como a nivel del derecho internacional y sus especialidades. Es decir, el principio pro homine no solo complementa un diálogo progresivo de protección de derechos, sino que también contribuye a reformar el diálogo legislativo y judicial, en cuanto a la formulación de políticas públicas sólidas, y a mejorar el diálogo entre los diferentes órganos que integran la judicatura en un país, y a la vez entre estos.

Los diferentes niveles de protección de los derechos humanos y sus respectivos roles en el diálogo internacional

La materialización del diálogo multinivel se encuentra plasmada en diversos niveles universales, regionales y nacionales de protección de los derechos humanos.

\section{Nivel universal}

A nivel universal, el nacimiento del sistema de Naciones Unidas ha tenido siempre presente la necesidad de cooperar con los diferentes actores para garantizar el mejor nivel de protección de los derechos humanos. Esta necesidad de cooperación y diálogo se ha visto plasmada en sus documentos fundacionales, como la Carta de las Naciones Unidas, que en sus artículos 1.3. y 1.4 precisa:

19. Sobre el progreso en América Latina, véase Piovesan (2017). 
Realizar la cooperación internacional en la solución de problemas internacionales de carácter económico, social, cultural o humanitario, y en el desarrollo y estímulo del respeto a los derechos humanos y a las libertades fundamentales de todos, sin hacer distinción por motivos de raza, sexo, idioma o religión.

Servir de centro que armonice los esfuerzos de las naciones para alcanzar estos propósitos comunes.

Estos esfuerzos de cooperación, que se traducen en un proceso dialógico entre el rol impulsor -intermediador que tiene Naciones Unidas y el rol receptor- y el ejecutor de los Estados, se han visto plasmados en diferentes pronunciamientos del organismo para hacer frente a crisis humanitarias y de derechos humanos que afrontan los diferentes países. También se han plasmado en promover el diálogo entre los Estados, la sociedad civil y demás actores para lograr fines comunes. Como ejemplo de ello, tenemos el lanzamiento por parte de Naciones Unidas de la iniciativa ONU75, que busca este año 2020 lograr una conversación amplia e inclusiva sobre el papel de la cooperación mundial para construir un futuro mejor a nivel global. ${ }^{20}$

\section{Nivel regional}

A nivel regional, contamos con diversos sistemas de protección y promoción de derechos humanos, como el Sistema Interamericano, Europeo, Africano ${ }^{21}$ y Asiático ${ }^{22}$ de Derechos Humanos. No obstante, en el presente artículo nos abocaremos a los dos primeros.

El Sistema Interamericano, cuya creación es anterior al Sistema Universal de Derechos Humanos, también fue fundado por la necesidad de diálogo entre los actores que intervienen en ella. Tal es así que, en el preámbulo de la Declaración Americana de los Derechos y Deberes del Hombre, se especifica:

20. «Dialogar con la ONU para conseguir un mundo mejor está a tu alcance», Noticias ONU, 2 de enero de 2020, disponible en https://bit.ly/2DjcYXr.

21. En el Sistema Africano de Derechos Humanos se puede revisar el preámbulo de la Carta Africana de Derechos Humanos y de los Pueblos: «Reafirmando la promesa que hicieron en el artículo 2 de dicha Carta de erradicar de África toda forma de colonialismo, coordinar e intensificar su cooperación y esfuerzos por alcanzar una vida mejor para los pueblos de África y fomentar la cooperación con la debida consideración a la Carta de las Naciones Unidas y a la Declaración de los derechos humanos».

22. En el Sistema Asiático de Derechos humanos se puede revisar el prólogo de la Declaración Asiatica de Derechos Humanos: «Reafirmando aún más nuestro compromiso con la Declaración Universal de Derechos Humanos, la Carta de las Naciones Unidas, la Declaración y el Programa de Acción de Viena y otros instrumentos internacionales de derechos humanos en los que los Estados miembros de la ASEAN son partes [...] Convencidos de que esta Declaración ayudará a establecer un marco para la cooperación en materia de derechos humanos en la región y contribuir al proceso de construcción de la comunidad de la ASEAN». 
La consagración americana de los derechos esenciales del hombre unida a las garantías ofrecidas por el régimen interno de los Estados, establece el sistema inicial de protección que los Estados americanos consideran adecuado a las actuales circunstancias sociales y jurídicas, no sin reconocer que deberán fortalecerlo cada vez más en el campo internacional, a medida que esas circunstancias vayan siendo más propicias (el énfasis es nuestro).

Por otro lado, la Carta Democrática Interamericana señala en sus artículos 14 y 26 , respectivamente:

Los Estados miembros acuerdan examinar periódicamente las acciones adoptadas y ejecutadas por la Organización encaminadas a fomentar el diálogo, la cooperación para el desarrollo integral y el combate a la pobreza en el hemisferio, y tomar las medidas oportunas para promover estos objetivos. ${ }^{23}$

La OEA mantendrá consultas y cooperación continua con los Estados miembros, tomando en cuenta los aportes de organizaciones de la sociedad civil que trabajen en esos ámbitos.

Por su parte, la Convención Americana sobre Derechos Humanos (CADH) señala en su preámbulo:

Reconociendo que los derechos esenciales del hombre no nacen del derecho de ser nacional de determinado Estado, sino que tienen como fundamento los atributos de la persona humana, razón por la cual justifican una protección internacional, de naturaleza convencional coadyuvante o complementaria de la que ofrece el derecho interno de los Estados americanos.

Por ende, los fundadores del Sistema Interamericano dejaron clara y expresa su convicción de que el diálogo, plasmado en un deber de cooperación entre los Estados, es esencial para lograr una mayor protección de los derechos humanos. Este diálogo ha sido plasmado tanto como una necesidad para asegurar los derechos existentes, como para avanzar en la regulación de nuevas circunstancias y hacerlas judiciales ante la Corte IDH, sobre la base de la jurisprudencia ya conocida referente a que la interpretación del derecho debe hacerse acorde con los nuevos tiempos y necesidades. ${ }^{24}$ Esto es lo que se conoce como diálogo jurisprudencial ${ }^{25} \mathrm{O}$

23. El énfasis en ésta y las siguientes citas es nuestro.

24. «El derecho a la información sobre la asistencia consular en el marco de las garantías del debido proceso legal», Corte Interamericana de Derechos Humanos, Opinión Consultiva OC-16/99, serie A núm. 16, 1 de octubre de 1999, párr. 55.

25. El Juez Eduardo Ferrer Mac-Gregor entiende por diálogo jurisprudencial: «La práctica de las cortes nacionales e internacionales a través de la cual se utiliza la argumentación de otras cortes con el fin de construir a una mejor interpretación de las normas de derechos humanos, y en general, de cualquier 
«fertilización recíproca» entre diferentes sistemas de protección de los derechos humanos.

Este diálogo se ha expresado, por ejemplo, con el reconocimiento de nuevos derechos a nivel interamericano que pueden llegar a ser justiciables ante la Corte IDH, como el derecho a un medio ambiente sano y equilibrado, el derecho al trabajo o el derecho al agua, entre otros. ${ }^{26} \mathrm{La}$ apertura de dichos criterios jurisprudenciales requiere necesariamente de un debate a nivel internacional, además de con los Estados y la sociedad civil, respecto de las expectativas sobre cómo estos van a ser implementados a nivel interno de los Estados.

En cuanto al Sistema Europeo, el Convenio Europeo de Derechos Humanos (CEDH) de 1950 y la jurisprudencia del Tribunal Europeo de Derechos Humanos (TEDH) siguen siendo las principales referencias en materia de derechos humanos a nivel regional (Fix-Zamudio, 2006: 1.105), complementados por la Carta Social Europea de 1961, que regula los derechos de carácter socioeconómicos a nivel regional. Sin embargo, la Carta de Derechos Humanos de la Unión Europea se hizo legalmente vinculante para todos los países miembros de la Unión Europea -con excepción de Polonia y el Reino Unido- con la entrada en vigor del Tratado de Lisboa en diciembre 2009. Entonces, es posible afirmar que en la actualidad en Europa existe un sistema tripolar de protección de los derechos humanos, compuesto por dos sistemas regionales distintos y los respectivos sistemas nacionales. Estos instrumentos europeos señalan de igual manera la importancia del diálogo multinivel, como señalamos a continuación.

El Convenio Europeo de Derechos Humanos, en su preámbulo, establece:

Considerando que la finalidad del Consejo de Europa es realizar una unión más estrecha entre sus miembros, y que uno de los medios para alcanzar esta finalidad es la protección y el desarrollo de los derechos humanos y de las libertades fundamentales.

Resueltos, en cuanto Gobiernos de Estados europeos animados por un mismo espíritu y en posesión de un patrimonio común de ideales y tradiciones políticas, de respeto a la libertad y de primacía del derecho, a tomar las primeras medidas adecuadas para asegurar la garantía colectiva de algunos de los derechos enunciados en la Declaración Universal.

Asimismo, la Carta de Derechos Humanos de la Unión Europea precisa en su preámbulo:

otra norma contenida en una constitución o en un tratado» (citado en Rodríguez Reveggino, 2017: 106).

26. Sentencia del caso Comunidades Indígenas Miembros de la Asociación Lhaka Honhat (Nuestra Tierra) con Argentina, Corte Interamericana de Derechos Humanos, fondo, reparaciones y costas, serie C núm. 400, 6 de febrero de 2020 . 
Consciente de su patrimonio espiritual y moral, la Unión está fundada sobre los valores indivisibles y universales de la dignidad humana, la libertad, la igualdad y la solidaridad, y se basa en los principios de la democracia y del Estado de derecho. Al instituir la ciudadanía de la Unión y crear un espacio de libertad, seguridad y justicia, sitúa a la persona en el centro de su actuación.

Esto demuestra que, a nivel del Consejo de Europa y la Unión Europea, el diálogo multinivel es esencial para el desarrollo armónico de ambas organizaciones. Más propiamente, a nivel de la Unión Europea, su Tratado de Funcionamiento regulan en sus artículos 151 al 156 el diálogo social que tiene como objetivo la mejora de la gobernanza europea, a través de la participación de los interlocutores sociales (representantes de las empresas y de los interlocutores) en la toma de decisiones y su aplicación. ${ }^{27}$ Por otra parte, a nivel del Consejo de Europa, se cuenta con el Libro Blanco sobre Diálogo Intercultural, en el cual se destaca la necesidad de dialogar para evitar divisiones étnicas, religiosas, lingüísticas y culturales, y así avanzar en el reconocimiento de las diferentes identidades de manera constructiva y democrática, según valores universales comunes. ${ }^{28}$

\section{Nivel nacional}

Por último, a nivel nacional, el diálogo se materializa principalmente en el marco de las normas constitucionales y las disposiciones de gobierno de cada uno de los países. Como son muy diversas, no podemos mencionar todas en esta sección.

Sin embargo, a nivel de un Estado cuyo modelo es unitario y no federalista, quizás el diálogo se presenta en algún sentido más sencillo, en el entendido de que se está frente a un Gobierno central y en donde los departamentos o estados a nivel interno no tienen una legislación diferente entre sí. No obstante, en países con regímenes federales, como México y Alemania, el desafío es mayor, pues se cuenta con las constituciones de los estados federados, así como las diferentes políticas públicas que se han forjado en el marco de esa división soberana. ${ }^{29}$ En países con un sistema federal - por beneficioso que pueda ser en otros aspectos- pueden presentarse preguntas complejas sobre la relación y las competencias en materia de tutela de derechos, sobre

27. «Fichas temáticas sobre la Unión Europea: El diálogo social», Parlamento Europeo, enero de 2020, disponible en https://bit.ly/3gRuRtY.

28. «Libro Blanco sobre el Diálogo Intercultural: Vivir juntos con igual dignidad», Consejo de Europa, publicado por los Ministerios de Asuntos Exteriores del Consejo de Europa en su 118. a sesión ministerial. Estrasburgo, 7 de mayo de 2008, p. 3.

29. El 26 de enero de 2016 fue promulgada la Reforma Política que dio paso a que la Ciudad de México se convirtiera en la entidad número 32 del país, con autonomía en lo concerniente a su régimen interior y a su organización política y administrativa. En ese sentido, también contará con una carta de derechos propia. 
todo si el nivel de protección regional de derechos humanos es más garantista que el nivel nacional y viceversa. ${ }^{30}$

\section{Tipos de diálogo entre los diferentes sistemas de protección de derechos humanos}

En el ecosistema de protección de los derechos humanos mencionados se deberían de llevar a cabo diálogos de diferente tipo, como veremos a continuación.

\section{Diálogo vertical}

El diálogo vertical es aquél que se presenta frente a actores cuyo nivel de interlocución no es entre pares; o, hablando con la lógica clásica del derecho internacional público, que no tienen el mismo nivel jerárquico. Este diálogo se presenta regularmente entre los organismos políticos y jurisprudenciales internacionales o regionales respecto de los Estados que tienen obligaciones internacionales frente a estos, y entre los Estados y sus respectivas dependencias estatales y demás actores sociales.

En las Américas, este tipo de diálogo puede verse reflejado en la aplicación del control de convencionalidad. Los Estados no solo tienen el deber de alinear su legislación nacional tratando de armonizarla (control de convencionalidad legislativo), sino también deben promover prácticas a nivel de políticas públicas que coadyuven a la protección de los derechos humanos (control de convencionalidad a nivel de políticas públicas). Este deber requiere de un diálogo vertical para su plena efectividad y evitar generar responsabilidades a nivel internacional, pues los Estados necesitan buscar una coherencia en el actuar de sus propias dependencias estatales, que incluye necesariamente a sus organismos judiciales.

Ahora bien, este diálogo vertical no requiere ser «jerárquico» en el sentido tradicional. Es decir, no es necesario que la normativa o jurisprudencia de un organismo judicial o político de rango más alto siempre prevalezca sobre la normatividad o jurisprudencia del organismo más «bajo». Como hemos visto, en virtud de los principios pro homine y complementariedad, incluso los tribunales de inferior jerarquía o autoridades locales de menor rango podrían adoptar políticas o estándares jurisprudenciales que ayuden a cumplir las obligaciones internacionales de los Estados o incluso ser más garantistas.

Un ejemplo europeo de esto lo podemos ubicar en la jurisprudencia del Tribunal Constitucional de España sobre el derecho a un juez imparcial, en que el tribunal asumió la doctrina de la doble dimensión de la imparcialidad desarrollada por el

30. El 5 de febrero de 2017 fue publicada la Constitución Política de la Ciudad de México, y de inmediato fue impugnada por la Suprema Corte de Justicia de la Nación argumentando, entre otras, la invasión de competencias federales. Véase Velasco (2018: 34). 
$\mathrm{TEDH},{ }^{31}$ al declarar inconstitucional una ley que permitía al juez de instrucción resolver también el caso en un proceso penal..$^{32}$ Otro ejemplo europeo lo vemos en la década de los 2000, cuando hubo algunos problemas de cumplimiento de las sentencias del TEDH en Alemania. Esto se evidenció en la «histórica contienda» o el «juego de ping-pong» entre el Tribunal Constitucional Federal de Alemania y el TEDH en los casos de la princesa Caroline de Mónaco. El Tribunal y el TEDH tuvieron ideas diferentes respecto de la «clásica» ponderación entre la libertad de prensa y el derecho a la vida privada y familiar, ${ }^{33}$ así como en la aplicación de la detención preventiva ilimitada de manera retroactiva que era posible en Alemania durante muchos años. ${ }^{34}$ Según el TEDH en su famoso caso $M$ con Alemania, ${ }^{35}$ existe una infracción a los artículos 5 y 7 de la CEDH cuando se viola el concepto nulla poena sine lege (no hay pena sin ley) y la aplicación de una pena de manera retroactiva.

Las diferencias, sobre todo respecto de estos dos casos, se explican porque la relación entre el TEDH y el Tribunal Constitucional alemán fue, durante muchos años, de tensión, competencia o confrontación, a veces incluso de conflicto abierto. En esta situación más o menos tensa, el acercamiento mutuo de las cortes alemanas y el TEDH en el caso Caroline ${ }^{36}$ y la revisión completa de la legislación frente a la prisión

31. Según esta jurisprudencia elaborada por el TEDH en la sentencia de los casos Piersack con Bélgica, núm. 8692/79, 1 de octubre 1982, y De Cubber con Bélgica, núm. 9186/80, 26 de octubre 1984, la imparcialidad de un juez cuenta con dos dimensiones distintas: «Un aspecto subjetivo, que trata de averiguar la convicción personal de un juez determinado en un caso concreto (que debía ser presumida mientras no se demuestre lo contrario), y un aspecto objetivo, que se refiere a si este ofrece las garantías suficientes para excluir cualquier duda razonable al respecto».

32. Sentencia 145/1988, Tribunal Constitucional de España, 12 de julio 1988.

33. Sentencias de los casos Von Hannover con Alemania, Tribunal Europeo de Derechos Humanos, núm. 59320/oo, 24 de junio de 2004; Von Hannover con Alemania (núm. 2), núm. 40660/o8 \& 60641/o8, 7 de febrero de 2012; y Von Hannover con Alemania (núm. 3), núm. 8772/10, 19 de septiembre de 2013.

34. El derecho penal de Alemania prevé la posibilidad de retener a una persona durante toda su vida, incluso después del cumplimiento de la pena más larga de privación de libertad que existe en el país (de 15 años). Si el delincuente todavía parece ser un peligro para la sociedad después del cumplimiento de la pena privativa de 15 años, el Estado puede ordenar su reclusión preventiva por interés superior de proteger a la generalidad. Esta forma de reclusión o detención — que según el entendimiento alemán no es una pena en sentido estricto, sino una medida de corrección y prevención- se podía aplicar incluso de manera retroactiva a la condena original.

35. Sentencia del caso M con Alemania, Tribunal Europeo de Derechos Humanos, núm. 19359/04, 17 de diciembre de 2009.

36. La corte civil más alta de Alemania (el Bundesgerichtshof, BGH), reaccionando al fallo del TEDH, tuvo que bajar el estándar de protección de la libertad de prensa, con una mejor ponderación de los derechos en juego y la introducción de un modelo de protección gradual: el concepto de los «personajes absolutos de la historia contemporánea» no justifica de manera general la prevalencia de la libertad de prensa. Más bien, se requiere una ponderación de cada caso teniendo en cuenta sus hechos específicos y viendo la contribución del artículo al debate público (sentencia del 6 de marzo de 2007, BGH, VI ZR 51/o6). A 
preventiva por el Parlamento alemán en 2015 adaptándola a la sentencia $M$, fueron recibidos con gran alivio. Los casos prueban que hoy nadie pone en duda que en general Estrasburgo y Karlsruhe tienen una relación de cooperación y diálogo en relación con el cumplimiento de las decisiones. El impacto de las sentencias del TEDH respecto de los fallos nacionales, logrado por el diálogo, es cada día más evidente.

\section{Diálogo horizontal}

El dialogo horizontal complementa el diálogo vertical en todo sentido. Este tipo de diálogo se presenta en forma regular entre organismos o actores que tienen el mismo nivel «jerárquico». Es decir, puede presentarse entre Estados, entre organismos regionales - sean o no de derechos humanos- y entre las diferentes dependencias estatales que sean homólogas entre sí, y frente a sus homólogos en otros países, como sucede con los tribunales o cortes constitucionales.

Este diálogo se presenta tanto entre los diferentes Estados dentro de una misma región, como a nivel interregional (Días y Mohallem, 2016: 273-276). Al respecto, los entonces presidentes del TEDH y de la Corte IDH, en el marco del diálogo transatlántico entre ambas cortes, señalaron:

La importancia de esta cooperación debe ser reconocida, dada la similitud de los derechos y libertades protegidos por los respectivos tratados fundacionales de ambas cortes, así como la existencia de ambos sistemas de criterios de admisibilidad y principios de interpretación muy parecidos. Además, la creciente convergencia en las temáticas planteadas ante ambas jurisdicciones confiere una nueva y mayor relevancia a sus respectivas jurisprudencias (TEDH y Corte IDH, 2015:3).

Ya desde hace muchos años se puede identificar una especie de cross-fertilization entre las experiencias del TEDH y la Corte IDH, por ejemplo en los temas de la desaparición forzada ${ }^{37} \mathrm{y}$ otras violaciones graves de derechos humanos, de grupos en situación de vulnerabilidad..$^{38}$ Cabe enfatizar que el TEDH ha sido una fuente ins-

continuación, el Tribunal Constitucional declaró compatible esta sentencia del BGH con la Constitución (BVerfG, 1 BvR 1602/07). Por su parte, unos años más tarde, el TEDH se acercó a la posición alemana y confirmó los resultados de la jurisprudencia alemana al respecto, después de su primera decisión en el caso Caroline de Mónaco, núm. 4066o/08 y 60641/o8 (Von Hannover II), 7 de febrero de 2012.

37. Entre otras cosas, la Corte IDH suele citar los siguientes fallos del TEDH para afirmar que la desaparición forzada constituye una violación grave de los derechos humanos: Kurt con Turquía, 25 de mayo de 1998; Çakici con Turquía, 8 de julio de 1999; Timurtas con Turquía, 13 de junio de 2000; Tas con Turquía, 14 de noviembre de 2000; y Chipre con Turquía, 10 de mayo de 2001. El TEDH, por su parte, ha seguido los fallos de la Corte IDH en considerar que la desaparición forzada constituye una violación continuada (Burgorgue-Larsen y Montoya, 2017: 201).

38. La Corte IDH citó, por ejemplo, varios fallos del TEDH en la sentencia del caso Poblete Vilches $y$ otros con Chile, serie C núm. 349, 8 de marzo 2018, párr. 128. 
piradora para la evolución de la jurisprudencia del SIDH y viceversa. Por ejemplo, la Corte IDH invocó por primera vez una sentencia del TEDH en la Opinión Consultiva 4/84, al referirse al principio de no discriminación, en que señala que la jurisprudencia europea ha dicho que «solo es discriminatoria una distinción cuando carece de justificación objetiva y razonable». ${ }^{39}$ Esto da a entender que a nivel del SIDH y SEDH ha existido un diálogo entre ambos tribunales regionales para avanzar en un ámbito solidario en el desarrollo jurisprudencial de normas que tutelan los derechos humanos desde diferentes realidades sociales.

Por otro lado, las motivaciones para entrar en tal diálogo horizontal son múltiples, tanto a nivel interregional como al nivel interestatal..$^{40}$ Como muchos Estados comparten problemas jurídicos similares, conviene considerar la jurisprudencia ya existente en otras jurisdicciones como fuente de inspiración, lo mismo a nivel local. También se utiliza la jurisprudencia foránea para corroborar la propia línea de argumentación y reforzar la autoridad de la decisión.

Además, se puede constatar un aporte a fomentar la aceptación y la eficacia de las obligaciones del derecho regional e internacional de los derechos humanos mediante una comparación con fallos de otras cortes constitucionales nacionales, un concepto conocido como transnational reciprocity (reciprocidad transnacional) (Weiler, 1994: 522). Por un lado, un Estado puede ser presionado a cumplir una obligación internacional sabiendo que los otros Estados miembros del Sistema ya la han aceptado y llevado a la practica en su orden legal interno; por otro lado, no menos importante, las cortes constitucionales pueden asegurarse de que la aplicación de dicha obligación no perjudique a $s u$ Estado, ya que todos la están cumpliendo. Por último, a través de la comunicación transjudicial, se crea una especie de deliberación colectiva que busca soluciones a problemas comunes (Slaughter, 1994: 119 y ss.). Sobre todo entre Estados que pertenecen al mismo sistema regional y bajo las mismas obligaciones, un principio legal ya reconocido en una jurisdicción puede ser adoptado y desarrollado por otros tribunales, hasta que se establezca un principio común.

Ahora bien, un factor que es de suma valía para el éxito de este diálogo horizontal es el mecanismo de coordinación entre los diferentes poderes y niveles administrativos del Estado, para dar cumplimiento a la implementación de políticas públicas, o la efectividad de una sentencia emitida a nivel local o a nivel regional. También hay que destacar que este tipo de diálogo e intercambio horizontal se fortalece, en particular, a través de encuentros regulares entre juristas, Estados y demás actores sociales

39. «Restricciones a la pena de muerte (artículos 4.2 y 4.4 Convención Americana sobre Derechos Humanos)», Corte Interamericana de Derechos Humanos, Opinión Consultiva OC-3/83, serie A núm. 3, 8 de septiembre de 1983, párr. 43 .

40. Véase, para un estudio extenso de las diferentes motivaciones y ventajas del intercambio transnacional, Slaughter (1994: 114 y ss.). 
que trabajan en promover y proteger los derechos humanos, como la Bienal Latinoamericana de Derechos Humanos o el Encuentro Anual de Tribunales, Cortes y Salas Constitucionales de América Latina, llevado a cabo por el Programa Estado de Derecho para Latinoamérica de la Fundación Konrad Adenauer desde hace 25 años.

\section{Diálogo interdisciplinario}

Por último, no es suficiente poner en marcha un diálogo solo entre juristas. Como la protección efectiva de los derechos humanos es un asunto de todos, tenemos que esforzarnos para pensar con originalidad en nuevos conceptos, y en medios para promoverlos y defenderlos. Otras disciplinas, como la sociología, la economía o las ciencias políticas suelen tocar temas relacionados con los derechos humanos con regularidad; sin embargo, la ciencia en general se fundamenta en la separación de las diferentes disciplinas. Todavía hace falta un diálogo interdisciplinario para superar esta clasificación estrecha de miras. Además, necesitamos acercar más los derechos humanos y sus instituciones a los ciudadanos por medios claros y fácilmente entendibles, como el arte, el periodismo o el cine para que, finalmente, resulten ser causa de todos.

\section{Rol de la sociedad civil como «embajadores del diálogo»}

A lo largo de este texto hemos resaltado la importancia de contar con un diálogo multinivel, que involucre a los sistemas regionales de derechos humanos y a los demás actores, como la sociedad civil activa y organizada.

La historia muestra que las personas que viven en comunidad siempre han participado en la toma de decisiones que las afectan (Racelis, 1993). Para nadie es ajeno que los diferentes niveles de protección de los derechos humanos forman parte de un universo complejo y multidimensional, que difícilmente subsistiría sin la participación de la sociedad civil. Tal es así que, por ejemplo, a nivel del SIDH existe un mayor rol propulsor por parte de las organizaciones de sociedad civil en el desarrollo de la jurisprudencia, debido a que pueden intervenir de manera directa en la representación de las víctimas ante sus organismos, como la CIDH y la Corte IDH. Ello, teniendo en cuenta que es un sistema que está basado en la centralidad de las víctimas. ${ }^{41}$ Situación que es un poco diferente en el caso del TEDH, cuyo estándar es más técnico y a veces percibido como alejado del justiciable. Por ejemplo, las organizaciones de sociedad civil solo podrían acudir al TEDH si sus integrantes han sido víctimas de violaciones a los derechos humanos, pero no para representar a víctimas en sí (Cichowski, 2010: 6-7).

41. Sentencia del caso Niños de la Calle (Villagrán Morales y Otros) con Guatemala, Corte Interamericana de Derechos Humanos, reparaciones (artículo 63.1 Convención Americana sobre Derechos Humanos), 26 de mayo de 2001. Véase también Cançado Trindade (2001: 3-68). 
Al ser tan diversas, las organizaciones de la sociedad civil han sido, a través del litigio estratégico, la voz viva para los Estados y los sistemas regionales e internacionales de derechos humanos para dar a conocer la realidad actual de sus países o regiones. Por ende, la comunidad internacional no puede fundamentarse en forma exclusiva en la voluntad individual de cada Estado (Cançado Trindade, 2005). En línea con ello, el profesor Celestino del Arenal mencionó:

La sociedad mundial no es ya un sistema exclusivamente interestatal y estatocéntrico, sino una sociedad cada vez más multicéntrica, a nivel de actores y, consecuentemente, más imprevisible y más inestable a nivel de estructuras y dinámicas, en el que el problema de la seguridad y la distribución del poder no se circunscribe solo a los Estados, ni se realiza exclusivamente en términos político-militares (Del Arenal, 2001: 27).

La sociedad civil ha hecho un trabajo muy importante como interlocutor del diálogo en los niveles de protección de los derechos humanos desde tres frentes. La primera, al promover la creación y aplicación de estándares internacionales, y su apoyo en el desarrollo de jurisprudencia. Prueba de ello podemos verlo en el papel importante que han tenido las organizaciones de protección de derechos del trabajador y organizaciones profesionales en la elaboración y conclusión de la Carta Social Europea (Leclerc, 1989: 181-202), así como en su rol activo dentro del litigio estratégico.

La segunda, en avanzar el diálogo sobre fenómenos políticos, económicos, sociales, científico-técnicos y culturales que afectan o podrían impactar a la ciudadanía en general (Ribeiro, 2010: 255), como lo podemos ver en la actualidad en las demonstraciones de los «Fridays for Future», en que solicitan se combata de una mejor manera el cambio climático.

La tercera, al operativizar los esfuerzos provenientes de organismos internacionales para que se desarrollen a nivel local o regional, como su apoyo en las etapas de preparación y seguimiento de las Conferencias de Río de Janeiro sobre Medio Ambiente de 1992, de la Conferencia de Viena sobre Derechos Humanos de 1993, de la Conferencia de Roma de 1998, que originó el Estatuto del Tribunal Penal Internacional, y más (Ribeiro, 2010: 260).

En contraste con los aportes de la sociedad civil mencionados, los desafíos que ellos enfrentan para lograr un diálogo efectivo dentro de los diversos niveles de protección de derechos humanos pasan principalmente por la falta de coordinación interna que pueda existir entre estos, y en la desconfianza en los sistemas regionales de derechos humanos y en los Estados respecto del cumplimiento de sus compromisos internacionales.

Para frenar ello, resultaría valioso fortalecer las bases internas de la sociedad civil y buscar un acercamiento más directo con el Estado y sus agentes, a fin de despejar dudas y lograr trabajos conjuntos. 


\section{A modo de conclusión: Nuestra apuesta y hacia dónde vamos}

En un mundo cada vez más globalizado e interdependiente, la protección y promoción efectiva de los derechos humanos, universales e indivisibles desde su concepción, se puede fortalecer solo a través de un diálogo multinivel profundo y tolerante, lo que nos lleva a un aprendizaje recíproco entre los diferentes organismos regionales e internacionales de derechos humanos, Estados, la academia y la sociedad civil.

De esta manera, buscamos aproximarnos al desarrollo de un «derecho global», que fortalezca la protección y promoción de los derechos humanos (Slaughter, 1994: 136), pero no uno monolítico, sino uno multidimensional y democrático, en donde todas las voces estén representadas y se busquen soluciones plausibles, en el marco de nuestras diversas realidades nacionales y regionales. A nivel jurisprudencial, apostamos a que las cortes regionales y otros tribunales internacionales impulsen un diálogo ecosistémico, bajo el cual actúen de manera armónica en sus funciones de corrección, confirmación y armonización de las leyes y jurisprudencia. La función de corrección, respecto de decisiones que, desde una perspectiva externa, pueden ser criticables. La función de confirmación, para determinar si las regulaciones que a nivel nacional se han adoptado han sido avaladas como convencionales. ${ }^{42} \mathrm{Y}$ la función de armonización, que se materializa en los diferentes estándares constitucionales europeos y latinoamericanos (Ferrer Mac-Gregor y Queralt, 2017: 133 y ss.).

El diálogo jurisprudencial también debe apostar por la integración regional y el multilateralismo, pues si bien sus decisiones se adoptan teniendo en cuenta las heterogeneidades y peculiaridades de sus Estados miembros, su jurisprudencia debe ir construyendo y fortaleciendo una especie de judicatura interamericana o europea compartida, que promueva la integración regional en el sentido de ampliar el debate sobre problemáticas comunes.

Por su parte, a nivel técnico-jurídico y político, apostamos por diálogos políticos bilaterales o multilaterales que fortalezcan las políticas internas de los Estados, las que se ven traducidas en la adopción de normatividades coherentes, ponderadas y armónicas. Este diálogo contribuiría también a mejorar la labor de monitoreo de la situación de derechos humanos de manera coordinada, lo que nos ayudará a combatir desafíos comunes que enfrentan todos nuestros países. Desafíos como la pobreza, la desnutrición, la migración forzada, el desempleo y las graves crisis sanitarias, como la que actualmente enfrentamos con el covid-19, y que pone en debate una vez más si en efecto estamos o no siguiendo de manera adecuada un diálogo ecosistémico a ni-

42. Véase Nußberger, «Auswirkungen der Rechtsprechung des Europäischen Gerichtshofs für Menschenrechte auf das deutsche Arbeitsrecht», ponencia para el simposio europeo del Tribunal Federal de Trabajo de Alemania en Erfurt, 26 y 27 de abril de 2012, p. 20, disponible en https://bit.ly/34S8phY. 
vel mundial. ${ }^{43}$ Frente a un fenómeno global como la pandemia, respuestas nacionales no coordinadas no son suficientes para capturar la magnitud de la crisis y encontrar las medidas adecuadas y eficientes para combatirla.

Por último, el diálogo multinivel ofrece una oportunidad única para fortalecer nuestras democracias liberales y la institucionalidad estatal, y para hacer frente a las tendencias nacionalistas, populistas y autoritarias descritas más arriba. De esta manera, aumentaremos nuestras capacidades técnicas y legales para crear un dialogo reflexivo pero basado en la realidad, en la evidencia y con sustento empírico y analítico, libre de romanticismos. Esto nos lleva a concluir que un adecuado diálogo ecosistémico, holístico e inclusivo tiene que ser constructivo, siempre orientado hacia el objetivo que todos compartimos: la plena garantía de los derechos humanos.

La Primera Bienal Latinoamericana de Estudios sobre Derecho Internacional de los Derechos Humanos hizo un valioso aporte a este objetivo de un diálogo multinivel, al brindar un espacio de intercambio floreciente entre juristas y con otras cátedras de los países latinoamericanos, con sistemas de protección de derechos humanos y diversos actores sociales. No obstante, estos temas deben seguir siendo fortalecidos. Por ello, este año 2020 continuaremos con este esfuerzo por promover el desarrollo de un diálogo multinivel durante la segunda Bienal que se celebrará en Bogotá, Colombia, país sede del Programa Estado de Derecho para Latinoamérica de la Fundación Konrad Adenauer, en conjunto con la Universidad de los Andes.

\section{Referencias}

Burgorgue-Larsen, Laurence (2011). «The powers of the Court to monitor compliance with its judgments». En The Inter-American Court of Human Rights: Case Law and Commentary. Oxford: Oxford University Press.

Burgorgue-Larsen, Laurence y Nicolás Montoya (2017). Los Sistemas Interamericano y Europeo de Protección de los Derechos Humanos. Lima.

Cançado Trindade, Antônio Augusto (2001). «Las cláusulas pétreas de la protección internacional del ser humano: El acceso directo de los individuos a la justicia a nivel internacional y la intangibilidad de la jurisdicción obligatoria de los tribunales internacionales de derechos humanos». En El sistema interamericano de protección de los derechos humanos en el umbral del siglo XXI. San José: Corte IDH

-. (2005). A recta ratio nos fundamentos do jus gentium como direito internacional da humanidade. Belo Horizonte: Del Rey.

43. Flávia Piovesan y Mariela Morales Antoniazzi, «COVID-19 and the need for a holistic and integral approach to human rights protection», Verbassungsbolg, 25 de abril de 2020, disponible en https://bit. ly/2Dif4qn. 
Carozza, Paolo (2003). «Subsidiarity as a structural principle of international human rights law». American Journal of International Law, 97 (1): 38-79. Disponible en https://bit.ly/2DihPbe.

Carozza, Paolo y Pablo Gonzalez (2017). «The final word? Constitutional dialogue and the Inter-American Court of Human Rights: A reply to Jorge Contesse». International Journal of Constitutional Law, 15 (2): 436-442. DOI: 10.1093/icon/moxo21.

Cichowsкi, Rachel (2010). Civil society and the European Court of Human Rights: Annual meeting of the American Political Science Association. Washington D. C.

Del Arenal, Celestino (2001). «La nueva sociedad mundial y las nuevas realidades internacionales: Un reto para la teoría y para la política». En Curso de derecho internacional y relaciones internacionales. Lejona: Editorial de la Universidad del País Vasco.

DíAs, Roberto y Michael Freitas Mohallem (2016). «El diálogo jurisdiccional sobre derechos humanos y el surgimiento de la red internacional de cortes constitucionales». En Luiz Arcado y Luca Mezzetti (editores), Diálogo entre cortes. Bogotá: Universidad Externado de Colombia.

Ferrer MAC-Gregor, Eduardo y Argelia Queralt (2017). «El control de convencionalidad americano y el efecto de cosa interpretada europea: ¿Dos caras de una misma moneda?». En Francisco García Roca y Encarnación Carmona (coordinadores), ¿Hacía una globalización de los derechos?: El impacto de las sentencias del Tribunal Europeo y de la Corte Interamericana. Madrid: Arazandi Thompson Reuters.

Fix-Zamudio, Héctor (2006). Protección internacional de los derechos humanos. Ciudad de México: Universidad Autónoma de México.

HernándeZ, Gerardo (2014). El principio pro homine. Tlaxcala: Universidad Autónoma de Tlaxcala, Centro de Investigaciones Jurídico-políticas.

Higgins, Rosalyn (1994). Problems and process: International law and how we use it. Oxford: Oxford University Press.

HuneEus, Alexandra (2011). "Courts resisting courts: Lessons from the Inter-American Court's struggle to enforce human rights». Cornell International Law Journal, 44 (3): 493-533. Disponible en https://bit.ly/3jG3xkt.

LECLERC, Akandji (1989). «El papel de los gobiernos en la elaboración, aplicación y evolución de la Carta Social Europea». En Manuel Lezertua y José Vida Soria, (organizadores), La Carta Social Europea en la perspectiva de la Europa del año 20oo: Coloquio conmemorativo del XXV Aniversario de la «Carta Social Europea. Madrid: CPMTSS.

MeLÉNDEZ, Florentín (2012). Instrumentos internacionales sobre derechos humanos aplicables a la administración de justicia. Buenos Aires: Programa Estado de Derecho para Latinoamérica de la Fundación Konrad Adenauer y la Universidad del Rosario. 
Negishi, Yota (2018). «The subsidiarity principle's role in allocating competences between human rights courts and states parties: The hybrid model of centralized and diffused conventionality control of domestic law». En Ius constitutionale commune na América Latina (pp. 125-160). Río de Janeiro: Juruá.

Nogueira Alcalá, Humberto y Gonzalo Aguilar Cavallo (2018). Control de convencionalidad interno: La aplicación del corpus iuris interamericano por los Estados parte de la Convención Americana sobre Derechos Humanos, en especial, las jurisdicciones nacionales. Santiago: Librotecnia.

PInTo, Mónica (1997). «El principio pro homine: Criterios de hermenéutica y pautas para la regulación de los derechos humanos». En Martín Abregú y Christian Courtis (editores), La aplicación de los tratados sobre derechos humanos por los tribunales locales. Buenos Aires: Editores del Puerto.

Piovesan, Flávia (2017). «Ius constitutionale commune latinoamericano en derechos humanos e impacto del Sistema Interamericano: Rasgos, potencialidades y desafíos». En Armin von Bogdandy, Mariela Morales Antoniazzi y Eduardo Ferrer Mac-Gregor (coordinadores), Ius constitutionale commune en América Latina: Textos básicos para su comprensión (pp. 181-206). Querétaro: Max Planck Institute e Instituto de Estudios Constitucionales del estado de Querétaro.

RaCELIS, Mary (1993). «Movilización a la población para el desarrollo social.: Enfoques y técnicas para la participación popular». En Bernardo Kliksberg (compilador), Pobreza, un tema impostergable: Nuevas respuestas a nivel mundial. Caracas: Centro Latinoamericano de Administración para el Desarrollo (CLAD), Fondo de Cultura Económica y el PNUD.

RibeIro, Renato (2010). «El rol de la sociedad civil organizada para el fortalecimiento de la protección de los derechos humanos en el siglo XXI: Un enfoque especial sobre los DESC». Revista IIDH, 51: 249-271. Disponible en https://bit.ly/31Lx8CP.

Rodríguez Reveggino, Bruno (2017). «¿El diálogo como arma? La lucha de los tribunales regionales contra la fragmentación del derecho internacional de los derechos humanos». Iuris Dictio, 20: 105-118. DOI: 10.18272/iu.v20i20.920.

SERNA DE LA GARZA, José (2017). «El concepto del ius commune latinoamericano en derechos humanos: Elementos para una agenda de investigación». En Armin von Bogdandy, Mariela Morales Antoniazzi y Eduardo Ferrer Mac-Gregor (coordinadores), Ius constitutionale commune en América Latina: Textos básicos para su comprensión (pp. 193-214). Querétaro: Max Planck Institute e Instituto de Estudios Constitucionales del estado de Querétaro.

Slaughter, Anne-Marie (1994). "A Typology of Transjudicial Communication». University of Richmond Law Review, 29 (1): 99-137. Disponible en https://bit. ly/2EDWNVq. 
Soley, Ximena y Silvia Steininger (2018). «Parting ways or lashing back? Withdrawals, backlash and the Inter-American Court of Human Rights». International Journal of Law in Context, 14 (2): 237-257. DOI: 10.1017/S1744552318000058.

TEDH, Tribunal Europeo de Derechos Humanos y Corte IDH, Corte Interamericana de Derechos Humanos (2015). Diálogo transatlántico: selección de jurisprudencia del Tribunal Europeo y la Corte Interamericana de Derechos Humanos. Oisterwijk: Wolf Legal Publishers.

Velasco, Ignacio Alonso (2018). «Discriminacion hacia mexicanos naturalizados para acceder a cargos públicos en México». Revista de Investigación Científica, 11 (22).

WATERs, Melissa (2017). «Creeping monism: The judicial trend toward interpretative incorporation of human rights treaties». Victoria University of Wellington Law Review, 107 (3): 628-705. Disponible en https://bit.ly/32Qxuaq.

Weiler, Joseph H. H. (1994). «A quiet revolution: The European Court of Justice and its interlocutors». Comparative Political Studies, 26 (4): 510-534. DOI: 10.1177/0010414094026004006.

\section{Sobre los autores}

Marie-Christine Fuchs es abogada. Doctora en Derecho de la Universität des Saarlandes, Saarbrücken, Alemania. Siguió estudios de maestría en Derecho Internacional Público, Derecho de la Unión Europea y Derechos Humanos en el Europainstitut de la misma universidad. Cursó estudios de licenciatura tanto en Derecho Alemán como en Derecho Francés. Ha sido investigadora asociada del Instituto Max Planck de Derecho Privado Extranjero y Derecho Internacional Privado en Hamburgo, así como investigadora y profesora asistente en el Europainstitut. Desde 2016 es directora del Programa Estado de Derecho para Latinoamérica de la Fundación Konrad Adenauer. Su correo electrónico es marie-christine.fuchs@kas.de. (D) https:// orcid.org/0000-0003-3696-3186.

Miguel Barboza López es abogado por la Universidad Católica de Santa María de Arequipa, Perú. Es maestro en Derecho Internacional de los Derechos Humanos por la Universidad de Notre Dame (Estados Unidos), donde se recibió con honores Magna Cum Laude. Fue abogado de la Secretaría Ejecutiva de la Comisión Interamericana de Derechos Humanos, y del Programa Amazonia de EarthRights International. Actualmente es Coordinador de Proyectos del Programa Estado de Derecho para Latinoamérica de la Fundación Konrad Adenauer, y consultor sobre jurisprudencia interamericana para Oxford University Press. Su correo electrónico es miguel.barboza@kas.de. (D) https://orcid.org/oooo-0o03-1486-3379. 
El Anuario de Derechos Humanos es una publicación semestral de referencia y consulta en materia de derechos humanos y campos afines. Busca ser un espacio de discusión de los temas centrales en el ámbito nacional e internacional sobre derechos humanos. Es publicado desde 2005 por el Centro de Derechos Humanos de la Facultad de Derecho de la Universidad de Chile.

\author{
EDITORA GENERAL \\ Claudia Iriarte Rivas \\ ciriarter@derecho.uchile.cl \\ EDITORA DE ESTE NÚMERO \\ Liliana Galdámez Zelada \\ lgaldamez@derecho.uchile.cl \\ SITIO WEB \\ anuariocdh.uchile.cl \\ CORREO ELECTRÓNICO \\ anuario-cdh@derecho.uchile.cl \\ LICENCIA DE ESTE ARTÍCULO
}

Creative Commons Atribución Compartir Igual 4.o Internacional

\author{
कै \\ La edición de textos, el diseño editorial \\ y la conversión a formatos electrónicos de este artículo \\ estuvieron a cargo de Tipográfica \\ (www.tipografica.io)
}

